\title{
Reoperation on prosthetic heart valves
}

\author{
Patient-specific estimates of in-hospital events
}

Reoperation on prosthetic heart valves is increasingly under consideration for both clinical and prophylactic indications. To determine the correlates of hospital events, including in-hospital mortality, new persisting neurologic deficit, and length of postoperative stay, a three-institution study of 2246 consecutive prosthetic valve reoperations performed on 1984 patients between 1963 and 1992 was undertaken. The combined experience ranged from high-risk patients coming moribund to the operating room to an important number of well individuals undergoing prophylactic reoperations on potentially failing valves. The risk-unadjusted hospital mortality was $10.8 \%$, neurologic deficit at hospital discharge $1.1 \%$, and length of stay 10 days (median). Multivariably determined correlates of outcome included age at reoperation, degree, severity, and acuity of impairment of cardiac function, extensiveness of valvular heart disease, coexisting morbid conditions, number of previous heart operations, and concomitant procedures. The risk-adjusted hospital mortality for the first elective reoperation in a good-risk patient was $1.3 \%$ (90\% confidence limits $0.3 \%$ to $4.4 \%$ ), neurologic deficit $0.3 \%$ (90\% confidence limits $0.02 \%$ to $1.8 \%$ ), and length of postoperative stay 7 days (90\% confidence limits 4 to 13), emphasizing the wide variance in outcome events. Equations were developed to permit wide application of the results of the study for quantitatively estimating the risk of outcome events based on individual preoperative patient characteristics. These estimates should be useful for informed patient consent, considerations of prophylactic valve replacement, and cost and resource use. (J THORAC CARDIOVASC SURG 1995;109:30-48)

Jeffrey M. Piehler, MD, Kansas City, Mo., Eugene H. Blackstone, MD, Birmingham, Ala., Kent R. Bailey, PhD (by invitation), Rochester, Minn., Michael E. Sullivan, MD

(by invitation), Portland, Ore., James R. Pluth, MD, Scottsdale, Ariz.,

Noel S. Weiss, MD, DrPH (by invitation), Seattle, Wash., Ron S. Brookmeyer, $\mathrm{PhD}$

(by invitation), Baltimore, Md., and James G. Chandler, MD (by invitation), Irvine, Calif.

From the Section of Cardiovascular Surgery, Department of Cardiovascular Diseases, Mid-America Heart Institute of Saint Luke's Hospital, Kansas City, Mo; the Division of Cardiothoracic Surgery, the Department of Surgery, the University of Alabama at Birmingham Medical Center, Birmingham, Ala.; the Department of Health Sciences Research, Mayo Clinic, Rochester, Minn.; the Center for Outcomes Research and Education for Sisters of Providence Health Care System, Portland, Ore.; the Division of Thoracic and Cardiovascular Surgery, Department of Surgery, Mayo Clinic Scottsdale, Scottsdale, Ariz.; the Department of Epidemiology, University of Washington, Seattle, Wash.; the Department of Biostatistics, The Johns Hopkins School of Hygiene and Public Health, Baltimore, Md.; and the Shiley Heart Valve Research Center, Irvine, Calif.

Read at the Seventy-fourth Annual Meeting of The American Association for Thoracic Surgery, New York, N.Y., April 24-27, 1994.

Address for reprints: Jeffrey M. Piehler, MD, Medical Plaza II, Suite 50, 4320 Wornall Rd., Kansas City, Mo. 64111.

Copyright (C) 1995 by Mosby-Year Book, Inc.

$0022-5223 / 95 \$ 3.00+0 \quad \mathbf{1 2 / 6 / 5 9 9 7 1}$
A ctual or threatened prosthetic heart valve dysfunction necessitates weighing the risks and benefits of reoperation versus retention of the prosthesis. ${ }^{1} \mathrm{Be}-$ cause prosthetic heart valve reoperation is uncommon, most single institutions report a small number of patients, ${ }^{2-9}$ which may not adequately represent the entire spectrum of patients for whom prosthetic valve reoperations might be considered. This is particularly true with regard to prophylactic explantation of valve prostheses in otherwise well patients. Further, these reports do not provide the means for numeric prediction of operative risk or other events for a given patient with a specific constellation of risk factors (so-called patient-specific estimates).

Therefore, three experienced academic centers analyzed their combined prosthetic valve reoperation experience to identify the incremental risk factors for hospital mortality, length of hospital stay, 
and the occurrence of nonfatal persistent neurologic deficit after prosthetic valve reoperation. With these risk factors identified, the next goal of the study was to present the data in the form of equations that could be used to estimate the patient-specific probability of outcomes, based on information available at the time reoperation was considered.

\section{Patients and methods}

Patients. In the combined experience of the Mayo Clinic ( $n=997$ reoperations; 1963 to August 1, 1991), the University of Alabama Medical Center and the Birmingham Veterans Affairs Medical Center $(n=861$ reoperations; 1975 to January 1, 1992), and St. Vincent Hospital and Medical Center and the Oregon Health Sciences University ( $n=388$ reoperations; 1965 to January 1 , 1991), 1984 consecutive patients underwent 2246 prosthetic valve reoperations; 217 of these patients, therefore, had two or more valve reoperations in these institutions. (Unless stated otherwise, throughout this manuscript the $n$ refers to the number of reoperations, not the number of patients, because each procedure was entered into the data set as an independent observation.) Included were all reoperations during which a previously placed aortic, mitral, or tricuspid valve prosthesis was replaced or repaired; the latter included suture closure of a periprosthetic leak, thrombectomy, or exchange of a prosthetic valve poppet (Appendix Table A-1). Operations that included one or more concomitant procedures, such as coronary artery bypass grafting, ascending aortic aneurysmectomy, or left ventricular aneurysmectomy were included (Appendix Table A-2). Replacements of rightsided valve conduits were excluded. The patient group consisted of 1395 male and 851 female patients, their ages ranging from 1.5 to 88 years at the time of reoperation (mean age $52 \pm 16$ years). The most common indications for reoperation were periprosthetic leakage without evidence of infection, degeneration of a bioprosthesis, and prosthetic valve endocarditis (Appendix Table A-3). Although the majority of patients had symptoms but were in hemodynamically stable condition and undergoing a first elective reoperation, the data set included such clinical extremes as prophylactic reoperations in symptom-free patients, valve reoperations for the second time or more, and reoperations in patients in cardiogenic shock. Important comorbidity existed at the time of 493 reoperations (Appendix Table A-4). The types of device in place before and after reoperation are shown in Appendix Table A-5, and the preoperative position of prosthetic valves is shown in Appendix Table A-6.

Outcome events. Death in the hospital (hospital mortality), nonfatal (in hospital) new persisting neurologic deficit, and length of stay in the hospital after reoperation among hospital survivors were the outcome events. Hospital mortality was defined as death at any time during the hospitalization for the reoperation, regardless of the length of that stay. Nonfatal persisting neurologic deficit was defined as a new, postoperative residual neurologic functional impairment not completely resolved at the time of discharge alive from the hospital.

Data. Definitions for a common set of relevant variables were established collaboratively before data collection. The information was assembled by extracting information from each patient's complete hospital record by a standardized review process. After this was completed, a number of records randomly selected from the entire group were re-reviewed by two or more reviewers, and this showed good consistency in interpretation and transfer of data from the hospital record to the study forms.

The collected variables were studied for reasonableness, for example, by comparing hemodynamic status with New York Heart Association (NYHA) class; by comparing age, height, weight, and body surface area; by verifying outcome events; by cross-checking variables according to the recorded pre-reoperation versus post-reoperation valve position. The data sets were then submitted to the University of Alabama at Birmingham for creation of the database. In compliance with the patient confidentiality required by each of the three institutional review boards, the database contained only noninformative patient identification.

Analysis. Correlation between variables was assessed; clusters of correlated variables were identified ${ }_{0}^{10}$ univariable associations of discrete variables to outcome were determined by two-way contingency table, and associations of continuous and ordinal variables to outcome were assessed by two-sample $t$ tests and logistic analyses. Multivariable logistic regression analysis was then performed for the outcome events hospital death and nonfatal neurologic deficit ${ }^{11}$; and linear regression was used to analyze the $\log -\log$ transformation of length of postoperative stay. The analyses were performed by nonautomated, directed techniques. ${ }^{12,13}$

The variables entered into the analyses are listed in Appendix Table B-1. All are known or can be anticipated at the time of considering a prosthetic valve reoperation. Thus, for example, global myocardial ischemic time was not considered; had it been, along with other factors available only at the time of performing the reoperation, it would have been identified as a risk factor $(P<0.0001)$, although it would lack interpretability in the face of the large number of different methods of myocardial protection that were used. Transformations of scale for continuous and ordinal variables were performed to choose the most appropriate mode of their numeric expression to match the assumptions of the logistic equation. ${ }^{14} \mathrm{~A} P$ value of 0.05 , based on the likelihood ratio test, was required for a variable to be retained in the final parsimoniously derived equation.

In conjunction with the overall multivariable analytic process, multiple subanalyses were made, with the general purpose of determining whether the analysis of the database as a whole was justified, as well as to assess the likelihood of interactions between certain variables. Thus, for example, institutions were analyzed separately, as were the valve positions. The consistency of the results across subsets supported the use of the entire database for the analysis and the lack of need for interaction terms. Some risk factors emerged with particularly strong relationships with outcome, and there was concern that the subset of 
patients with these risk factors might unduly influence the risk factor relationships found in the lower risk patients. Consequently, the experiences with reoperations in elective, hemodynamically stable, noninfected patients were analyzed separately. The consistency of predictions within this subset with those from the overall equation reinforced further the use of the database as a whole. On the basis of these analyses, and the consideration of interaction terms for these various subsets, the parsimonious risk factor equation was formulated. Solving this equation results in an estimate of the probability of hospital mortality after reoperation, accompanied by a measure of uncertainty (confidence limits [CLs]). All CLs portrayed are $90 \%$ CLs; when these are nonoverlapping, the $P$ value for the difference between the point estimates is nearly certain to be less than 0.05 .

Validation of the multivariable analyses. The directed nonautomated technique of performing the final multivariable analysis of hospital death was compared with an automated bootstrap resampling method to determine the selection frequency of the risk factors..$^{15}$ This latter was performed by automatic stepwise variable selection on 1000 data sets each consisting of the patients in 2246 reoperations, selecting randomly and independently each member of the data set from the original database. Thus a given patient was allowed to enter a given data set more than one time, or not at all, depending on chance; in fact, the membership of each of the 1000 data sets was different. The result was that the variables appearing most commonly in the 1000 analyses were the variables that appeared in the final equation presented in this paper (Appendix Table B-2). Also, the median number of variables retained in the automated analyses was 15 , a similar and slightly larger number than appeared in the final equation used in the paper (a positive validation).

Lacking an external database for validating the quantitative predictions from the equation, internal predictive validity was tested by numerous comparisons of the actual number of hospital deaths in stratified groups of patients with the number of deaths predicted for that specific group by summing the predicted probabilities of each of the individuals in the group, each obtained by a patientspecific solution of the multivariable analysis (Appendix Table B-3). Using a $\chi^{2}$ goodness of fit test and 1000 bootstrap samples to determine its sampling distribution, the $P$ values for the differences between actual and predicted were always 0.4 or larger. ${ }^{16}$

\section{Results}

Hospital death. Two hundred forty-three hospital deaths occurred among the 2246 reoperations $(10.8 \%$; CL $9.8 \%$ to $12.0 \%)$. Both the risk-unadjusted $\left(P\left(\chi^{2}\right)=0.3\right)$ and the risk-adjusted ( $P($ logistic) $=0.9)$ differences in hospital mortality among the three institutions could have been due to chance alone (Appendix Table B-3). By univariable analysis, there was no significant improvement in hospital mortality over the time of this study (Appendix Table A-7) $(P($ logistic $)=0.23)$; however, risk-adjusted mortality was found to be higher before 1970
$(P=0.02)$ (Table I). Having no relevance to current estimate of hospital events, this variable was not incorporated into the predictive equation.

Multivariable logistic regression analysis identified twelve other incremental risk factors for hospital mortality (Table I), all of which would be known preoperatively and which were incorporated into the predictive risk equation. Data pertaining to each of these variables, including their univariable $P$ values, are presented in table form (Tables II and III) in this section. Similar data pertaining to clinically important variables that were not retained in the predictive equation are presented in the appendix (Appendix Tables A-1 through A-8).

Patient incremental risk factors for hospital death. The patients' age and weight (inverse relation) at the time of reoperation were risk-adjusted (Table I) and risk-unadjusted (Table II) correlates of hospital death. Neither body surface area nor height was retained in the multivariable analysis once weight was entered. No evidence was found that including children undergoing valve reoperations confounded the analysis $(P=0.5)$; thus the predictive equation is applicable to both children and adults. A higher unadjusted risk among female patients, $13.0 \%$ (CL $11.8 \%$ to $14.3 \%$ ), compared with male patients, $9.5 \%$ (CL $8.6 \%$ to $10.3 \%$ ), appeared to be related to their smaller size.

The number of previous heart operations was a moderately strong risk factor for hospital mortality in both multivariable (Table I) and univariable (Table II) analyses. The number of previous heart operations was a stronger predictor of risk than number of previous valve reoperations, although the two variables were identical in most patients. Previous coronary artery bypass grafting had been performed in 233 patients. The hospital mortality in this group, $12.9 \%$ (CL $10.6 \%$ to $15.6 \%$ ), was not believably different from that in the group without previous coronary bypass, $10.6 \%$ (CL $9.9 \%$ to $11.4 \%$ ), in either analysis.

Variables that reflected poorer preoperative left ventricular function proved to be both risk-unadjusted and risk-adjusted strong correlates of hospital mortality, including NYHA functional class, hemodynamic instability, and the presence of tricuspid incompetence (as either a past or current diagnosis) (Tables I and II). Priority of the reoperation was a strong univariate predictor of hospital death but was not retained in the analysis, being subordinate to functional class and hemodynamic stability (Appendix Table A-8). 
Table I. Multivariable risk factors for hospital death after reoperation on valve replacement devices $(n=2246$; hospital deaths $=243$ )

\begin{tabular}{|c|c|c|}
\hline Incremental risk factors for hospital death & $\begin{array}{c}\text { Logistic } \\
\text { coefficient } \pm S D\end{array}$ & $P$ value \\
\hline \multicolumn{3}{|l|}{ Demographic } \\
\hline Age $^{*}$ (older) & $0.6427 \pm 0.127$ & $<0.0001$ \\
\hline Weight (lower) & $0.5270 \pm 0.158$ & 0.0008 \\
\hline No. of previous heart operations (higher) & $0.3310 \pm 0.103$ & 0.001 \\
\hline NYHA class $(\mathrm{I}-\mathrm{V}) \ddagger$ (higher) & $0.5744 \pm 0.099$ & $<0.0001$ \\
\hline Hemodynamic status (poorer) & $0.5647 \pm 0.111$ & $<0.0001$ \\
\hline Tricuspid incompetence (past or at reoperation) & $0.8647 \pm 0.21$ & $<0.0001$ \\
\hline Prosthetic valve infection & $1.151 \pm 0.196$ & $<0.0001$ \\
\hline Renal failure & $0.8859 \pm 0.35$ & 0.01 \\
\hline \multicolumn{3}{|l|}{ Surgical variables } \\
\hline $\begin{array}{l}\text { Aortic and mitral replacement devices in place at } \\
\text { end of reoperation }\end{array}$ & $0.5088 \pm 0.166$ & 0.002 \\
\hline $\begin{array}{l}\text { Repair of ascending aortic aneurysm by composite } \\
\text { graft technique }\end{array}$ & $1.498 \pm 0.37$ & $<0.0001$ \\
\hline Coronary artery bypass grafting & $0.6005 \pm 0.23$ & 0.009 \\
\hline Left ventricular aneurysmectomy & $1.993 \pm 0.71$ & 0.005 \\
\hline Reoperation before $1970 \S$ & $0.9420 \pm 0.40$ & 0.02 \\
\hline
\end{tabular}

Intercept -6.444. NYHA, New York Heart Association; $S D$, standard deviation.

* $[\text { Age (years) } / 50]^{2}$ squared transform of continuous variable.

$\dagger[70 /$ Weight $(\mathrm{kg})]$ inverse transform of continuous variable.

†Ordinal variable.

$\$ 0=$ Stable; 1 = hemodynamically unstable; 4 = cardiogenic shock (square transform of ordinal variable).

$\S$ Variable not used in prediction equation for current patients (see Appendix C).

Hospital mortality varied according to the clinical indication for reoperation (Appendix Table A-3). Prophylactic reoperations were associated with a mortality of $1.0 \%$, whereas reoperations for prosthetic valve endocarditis (Tables I and II) and for valve thrombosis carried a high risk. However, with the exception of prosthetic valve endocarditis (defined as present at the time of reoperation and the indication for the procedure), the wide variation in risk with operative indication is accounted for by the coexistence of other risk factors incorporated into the multivariable analysis.

Among numerous coexisting preoperative medical conditions (Appendix Table A-4), renal failure proved to have both univariable (Table II) and multivariable (Table I) correlation with hospital mortality.

Procedural incremental risk factors for hospital death. As stated earlier, global myocardial ischemic time was a strong predictor of hospital mortality $(P<0.0001)$ (Fig. 1), but it was not retained in the final multivariable analysis because of its uncertainty in the preoperative time frame. On the other hand, the need for concomitant repair of ascending aortic aneurysm by composite technique (but not with sim- ple interposition graft), left ventricular aneurysmectomy, or coronary artery bypass grafting can usually be anticipated. These variables were moderately strong predictors of hospital mortality in both univariable (Table III) and multivariable (Table I) analyses.

The actual procedure performed on the prosthesis at the reoperation-repair versus replacementdid not convincingly influence hospital mortality, although the prevalence of hospital deaths was appreciably lower after poppet replacement and after thrombectomy than after other procedures (Appendix Table A-1). Neither the type of prosthesis in place at reoperation nor the type of prosthesis implanted influenced hospital mortality (Appendix Table A-5). At reoperation, the highest risk was experienced by patients receiving a mitral xenograft. However, this observed increased risk was accounted for by the presence of other risk factors, implying that such valves were selectively placed in patients with greater underlying risk and perhaps perceived less life expectancy.

The location of the prosthetic valve pathology did influence hospital mortality, with prosthetic mitral valve reoperations having greater unadjusted mortality than those on a prosthetic aortic valve (Ap- 
Table II. The risk-unadjusted (actual) relation of preoperative patient variables to the hospital mortality

\begin{tabular}{|c|c|c|c|c|c|}
\hline \multirow[b]{2}{*}{ Patient variable } & \multirow[b]{2}{*}{$n$} & \multicolumn{3}{|c|}{ Hospital deaths } & \multirow{2}{*}{$\begin{array}{c}P \\
\text { (logistic) }\end{array}$} \\
\hline & & No. & $\%$ & $C L(\%)$ & \\
\hline \multicolumn{6}{|l|}{ Age at reoperation (yr) } \\
\hline$\geq \quad<$ & & & & & \multirow{7}{*}{0.0002} \\
\hline 18 & 63 & 7 & 11.1 & $5.6-20$ & \\
\hline $18 \ldots \ldots 40$ & 435 & 39 & 9.0 & $6.9-11.6$ & \\
\hline $40 \ldots \ldots 50$ & 381 & 29 & 7.6 & $5.6-10.3$ & \\
\hline $50 \ldots \ldots 60$ & 545 & 59 & 10.8 & $8.7-13.3$ & \\
\hline $60 \ldots \ldots 70$ & 573 & 66 & 11.5 & $9.4-14.0$ & \\
\hline 70 & 249 & 43 & 17.3 & $13.5-22$ & \\
\hline \multicolumn{6}{|l|}{ Weight at reoperation $(\mathrm{kg})$} \\
\hline$\geq \quad<$ & & & & & \multirow{8}{*}{0.0003} \\
\hline 50 & 134 & 23 & 17.2 & $12.1-24$ & \\
\hline $50 \ldots \ldots 60$ & 373 & 49 & 13.1 & $10.4-16.4$ & \\
\hline $60 \ldots \ldots 70$ & 502 & 50 & 10.0 & $7.9-12.5$ & \\
\hline $70 \ldots \ldots 80$ & 483 & 49 & 10.1 & $8.0-12.7$ & \\
\hline $80 \ldots \ldots 90$ & 284 & 21 & 7.4 & $5.1-10.6$ & \\
\hline 90 & 167 & 10 & 6.0 & $3.4-10.1$ & \\
\hline Unknown & 303 & 41 & 13.5 & $10.5-17.3$ & \\
\hline \multicolumn{6}{|l|}{ No. of previous heart operations } \\
\hline 1 & 1665 & 154 & 9.2 & $8.1-10.5$ & \multirow{6}{*}{$<0.0001$} \\
\hline 2 & 441 & 63 & 14.3 & $11.7-17.4$ & \\
\hline 3 & 103 & 17 & 16.5 & $11.0-24$ & \\
\hline 4 & 28 & 7 & 25 & $12.8-42$ & \\
\hline 5 & 5 & 1 & 20 & $1.4-65$ & \\
\hline Unknown & 4 & 1 & 25 & $1.7-74$ & \\
\hline \multicolumn{6}{|l|}{ NYHA class } \\
\hline I & 299 & 7 & 2.3 & $1.2-4.5$ & \multirow{6}{*}{$<0.0001$} \\
\hline II & 563 & 32 & 5.7 & $4.2-7.6$ & \\
\hline III & 854 & 78 & 9.1 & $7.6-11.0$ & \\
\hline IV & 425 & 91 & 21 & $18.2-25$ & \\
\hline $\mathrm{V}$ & 38 & 28 & 74 & $59-85$ & \\
\hline Unknown & 67 & 7 & 10.4 & $5.2-19.1$ & \\
\hline \multicolumn{6}{|l|}{ Hemodynamic status } \\
\hline Stable & 2098 & 188 & 9.0 & $8.0-10.1$ & \multirow{4}{*}{$<0.0001$} \\
\hline Unstable & 85 & 26 & 31 & $23-40$ & \\
\hline Shock & 36 & 26 & 72 & $57-84$ & \\
\hline Unknown & 27 & 3 & 11.1 & $3.5-27$ & \\
\hline \multicolumn{6}{|c|}{ Tricuspid incompetence (past or at reoperation) } \\
\hline No & 2035 & 198 & 9.7 & $8.7-10.9$ & \multirow[t]{3}{*}{$<0.0001^{*}$} \\
\hline Yes & 207 & 44 & 21 & $16.7-27$ & \\
\hline Unknown & 4 & 1 & 25 & $1.7-74$ & \\
\hline \multicolumn{6}{|l|}{ Prosthetic valve infection } \\
\hline No & 1993 & 185 & 9.3 & $8.2-10.4$ & \multirow[t]{3}{*}{$<0.0001^{*}$} \\
\hline Yes & 243 & 58 & 24 & $19.5-29$ & \\
\hline Unknown & 10 & 0 & 0 & $0-28$ & \\
\hline \multicolumn{6}{|l|}{ Renal failure } \\
\hline No & 2149 & 217 & 10.1 & $9.1-11.2$ & \multirow[t]{3}{*}{$<0.0001^{*}$} \\
\hline Yes & 57 & 19 & 33 & $23-45$ & \\
\hline Unknown & 40 & 7 & 17.5 & $8.9-31$ & \\
\hline Total & 2246 & 243 & 10.8 & $9.8-12.0$ & \\
\hline
\end{tabular}

$C L$, confidence limits; $N Y H A$, New York Heart Association.

${ }^{*} P\left(\chi^{2}\right)$.

pendix Table A-5 and A-6). This difference, however, was not identified after multivariate analysis, implying that the greater mortality in the mitral group was due to a higher prevalence of risk factors. Never- theless, the multivariate analysis did reveal that multiple valve disease, defined as aortic and mitral replacement devices in place at end of reoperation, was an incremental risk factor (Tables I and III). 
Table III. The risk-unadjusted relation of surgical variables to the hospital mortality

\begin{tabular}{|c|c|c|c|c|c|}
\hline \multirow[b]{2}{*}{ Surgical variable } & \multirow[b]{2}{*}{$n$} & \multicolumn{3}{|c|}{ Hospital deaths } & \multirow[b]{2}{*}{$P\left(\chi^{2}\right)$} \\
\hline & & No. & $\%$ & $C L(\%)$ & \\
\hline \multicolumn{6}{|c|}{$\begin{array}{l}\text { Aortic and mitral replacement devices in } \\
\text { place at end of procedure }\end{array}$} \\
\hline No & 1733 & 167 & 9.6 & $8.5-10.9$ & 0.0009 \\
\hline Yes & 513 & 76 & 14.8 & $12.3-17.7$ & \\
\hline \multicolumn{6}{|c|}{$\begin{array}{l}\text { Repair of ascending aortic aneurysm by } \\
\text { composite graft technique }\end{array}$} \\
\hline No & 2197 & 229 & 10.4 & $9.4-11.6$ & $<0.0001$ \\
\hline Yes & 49 & 14 & 29 & $18.4-41.2$ & \\
\hline \multicolumn{6}{|l|}{ Coronary artery bypass grafting } \\
\hline No & 2050 & 211 & 10.3 & $9.2-11.5$ & 0.009 \\
\hline Yes & 196 & 32 & 16.3 & $12.2-21.4$ & \\
\hline \multicolumn{6}{|l|}{ Left ventricular aneurysmectomy } \\
\hline No & 2228 & 239 & 10.7 & $9.7-11.9$ & 0.003 \\
\hline Yes & 10 & 4 & 40 & $16.0-69$ & \\
\hline Unknown & 8 & 0 & 0 & $0-34$ & \\
\hline \multicolumn{6}{|l|}{ Reoperation before 1970} \\
\hline No & 2183 & 234 & 10.7 & $9.7-11.9$ & 0.4 \\
\hline Yes & 63 & 9 & 14.3 & $7.9-24$ & \\
\hline Total & 2246 & 243 & 10.8 & $9.8-12.0$ & \\
\hline
\end{tabular}

$C L, 90 \%$ confidence limits.

Prediction equation for hospital mortality. The twelve preoperative incremental risk factors for hospital mortality listed in Table I were analyzed as described to generate the predictive equation. In Appendix Table $\mathrm{C}$, the variables are presented in detail, with their transformations of scale, logistic coefficients, and variance-covariance matrix, in a form suitable to program a small calculator or computer to generate a patient-specific numeric estimate of hospital mortality and its degree of uncertainty. If only a few variables are under consideration, the equation can be used to construct nomograms depicting the contributions of various factors in affecting hospital mortality (Figs. 2 and 3).

Persisting new neurologic deficit at hospital dismissal. Among the 2003 hospital survivors, 22 $(1.1 \%$, CL $0.8 \%$ to $1.6 \%)$ had a persisting new neurologic deficit. A multivariable analysis looking for incremental risk factors for this event was unsuccessful because of the relatively small number of events. However, the risk of such an event did correlate with predicted hospital mortality as estimated by the risk equation (Table IV and Fig. 4).

Length of hospital stay. The median interval between the reoperation and hospital discharge was 10 days; the 25th and 75th percentiles were 8 and 14 days, respectively, and the 10th and 90th were 7 and 23 days (Fig. 5).

The non-risk-adjusted effect of preoperative NYHA class on length of stay is shown in Fig. 6, and the

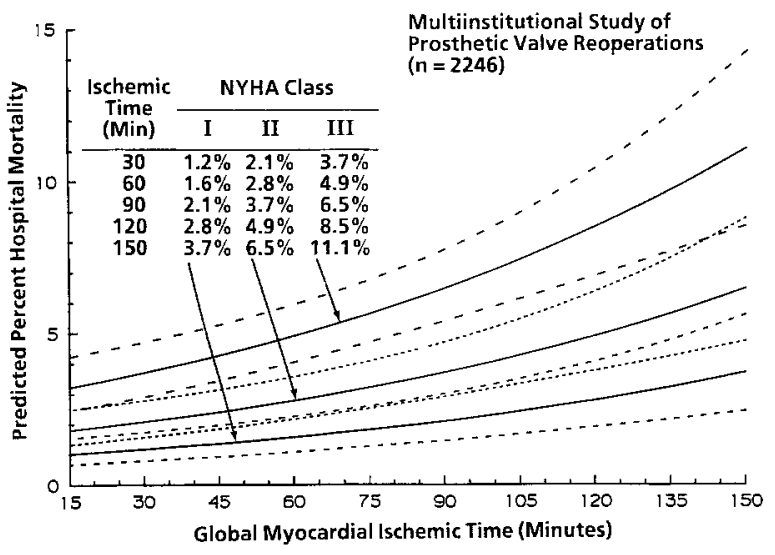

Fig. 1. The risk-adjusted relation between global myocardial ischemic time and NYHA functional class on predicted hospital mortality after a first reoperation under stable conditions without endocarditis, concomitant risk factors, or additional surgical procedures. The depiction is a nomogram of a specific solution of the predictive multivariable risk equation (Appendix Table C). The dashed lines enclose the 90\% CLs around the continuous point estimates.

risk-adjusted effect, along with the risk-adjusted effect of age at reoperation, in Table V. Other risk factors increasing length of stay included an earlier era (earlier date of reoperation), a poor preoperative hemodynamic state, extensiveness of the valve disease, a more extensive procedure performed at reoperation, and one institution (Appendix Table D-1). 

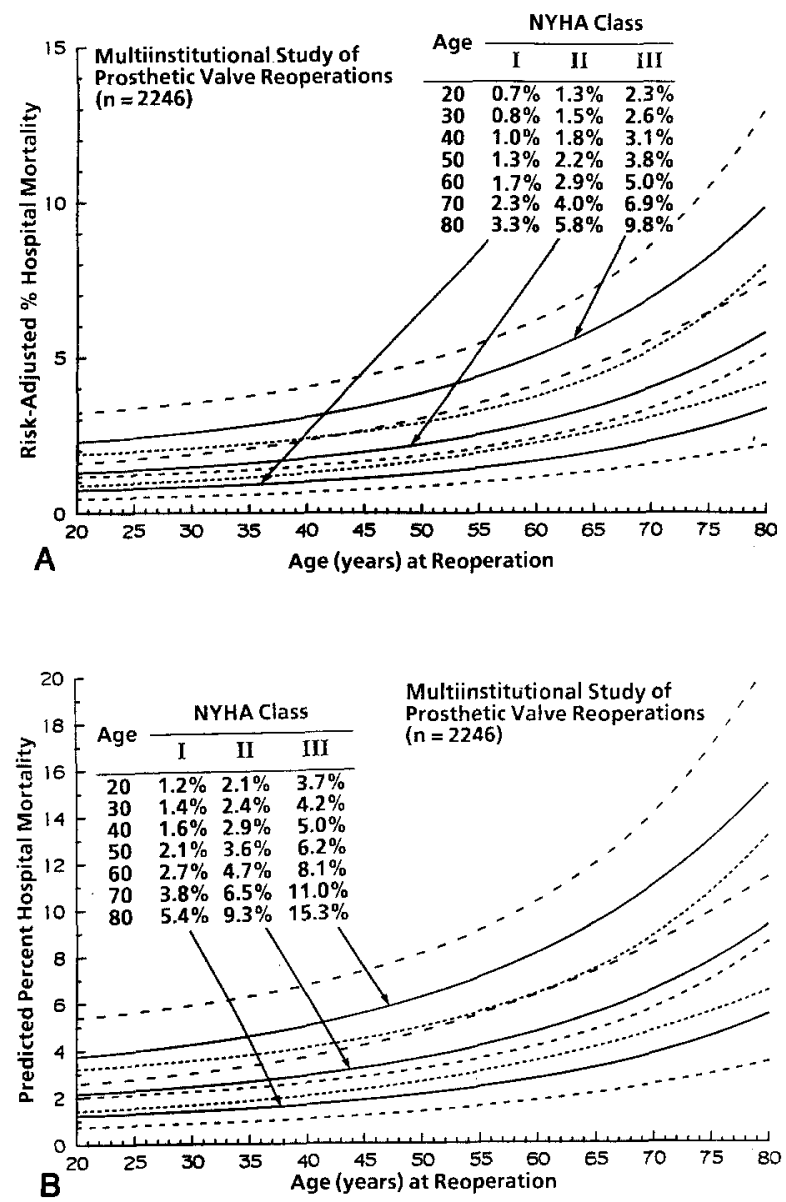

Fig. 2. The risk-adjusted relation between age at reoperation and NYHA functional class on predicted hospital mortality after a first reoperation under the same conditions outlined in Fig. 1. The depiction is a nomogram of a specific solution of the predictive multivariable risk equation (Appendix Table C). The depiction is as for Fig. 1. A, Single valve disease (aortic or mitral). B, Double valve disease (aortic and mitral).

\section{Discussion}

Nature of the risk factors surrounding reoperation on a prosthetic valve. This study confirms the experiences of others in identifying variables that are associated with incremental risk of hospital mortality after prosthetic valve reoperations..$^{2-9}$ The impact of most of the risk factors identified in this study on reoperative death is largely intuitive, and similar observations have also been made for mortality after primary valve replacement. ${ }^{17-21}$ Thus such factors as older age, higher NYHA class, decompensated hemodynamic status, extensiveness of valve disease, need for concomitant procedures,

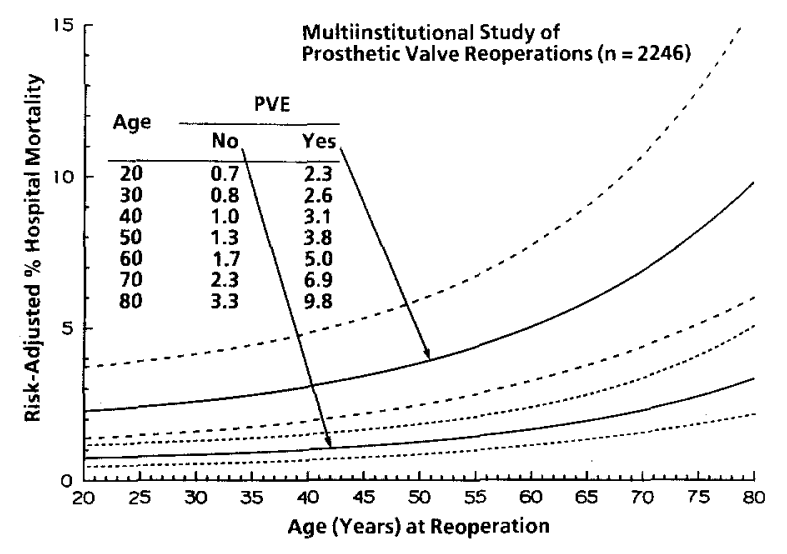

Fig. 3. The risk-adjusted relation between age at reoperation and the presence of prosthetic valve endocarditis $(P V E)$ on predicted hospital mortality after a first reoperation on a single prosthetic valve in the current era in a $70 \mathrm{~kg}$, hemodynamically stable patient in NYHA class I. The depiction is a nomogram of a specific solution of the predictive multivariable risk equation (Appendix Table C). The depiction is as for Fig. 1 .

Table IV. The prevalence of persisting neurologic deficits at hospital dismissal in the 2003 patients leaving the hospital alive after a reoperation on a valve replacement device, according to the predicted hospital mortality of the patients. (For this, the predicted mortality for each of the 2003 patients was determined, using the equation in Table I, and the stratification was based on this.)

\begin{tabular}{|c|c|c|c|c|}
\hline $\begin{array}{c}\text { Predicted hospital } \\
\text { mortality }(\%)\end{array}$ & \multirow[b]{2}{*}{$n$} & \multicolumn{3}{|c|}{$\begin{array}{c}\text { Persisting neurologic deficit } \\
\text { at hospital dismissal }\end{array}$} \\
\hline$<$ & & No. & $\%$ & $C L(\%)$ \\
\hline 2 & 289 & 1 & 0.3 & $0.02-1.8$ \\
\hline $2 \ldots 5$ & 603 & 4 & 0.7 & $0.2-1.6$ \\
\hline $5 \ldots 10$ & 531 & 6 & 1.1 & $0.5-2.3$ \\
\hline $10 \ldots 20$ & 391 & 6 & 1.5 & $0.7-3.1$ \\
\hline 20 & 189 & 5 & 2.6 & $1.1-5.7$ \\
\hline Total & 2003 & 22 & 1.1 & $0.8-1.6$ \\
\hline$P(\operatorname{logistic})$ & & & 0.004 & \\
\hline
\end{tabular}

$C L, 90 \%$ confidence limits.

and presence of infection are consistently identified as contributors to greater operative risk. Because most patients in the study had aortic and/or mitral valve disease, the left ventricle can be considered to be the ventricle most likely impaired. Thus left ventricular dysfunction is probably responsible for preoperatively higher NYHA class, hemodynamic instability, and tricuspid insufficiency. This dysfunc- 


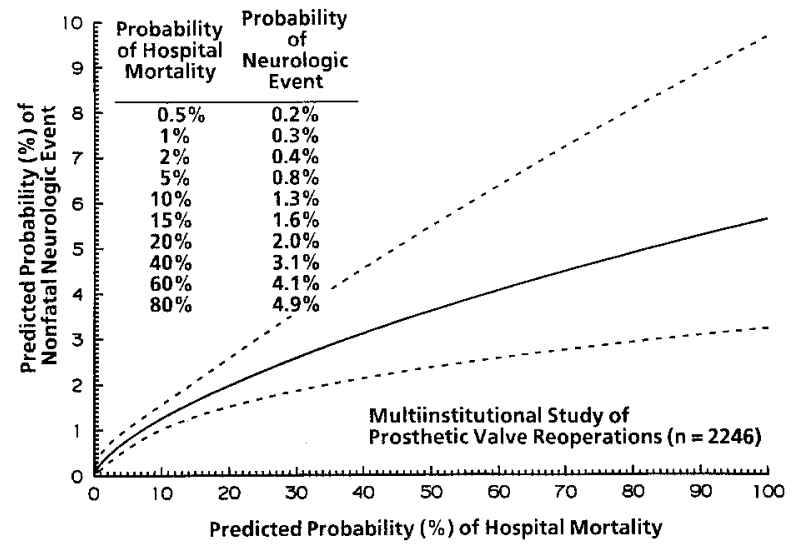

Fig. 4. The relation between predicted probability of hospital mortality after reoperation on a prosthetic heart valve (as determined by the multivariable risk equation of Appendix Table C) and predicted probability of a nonfatal persistent postoperative neurologic event. The dashed lines enclose the $90 \%$ CLs around the continuous point estimates.

tion is probably responsible for much of the mortality that is associated with these reoperations, and the inference that mortality could be lessened by earlier reoperation before the onset of left ventricular decompensation would appear valid.

The process of identifying pertinent risk factors results in some observations that are not clinically intuitive. For example, such variables as the location or type of malfunctioning valve, the procedure performed (repair or re-replacement), or the type of valve inserted proved to be of minimal predictive value once risk-adjusted estimates of mortality were made. This would indicate that other variables, such as technical factors involved with sternal reentry, myocardial preservation, and valve exposure, are of paramount importance in determining operative risk. The strong correlation between global myocardial ischemic time and hospital mortality would support this contention.

A different set of risk factors (Appendix Table D-1) was found to correlate with length of hospital stay after reoperation, although there was considerable overlap with the incremental risk factors associated with hospital mortality (Table I). Because the cost and resource use of these procedures are related to some extent to the duration of hospitalization, the existence of extreme values for some of the risk factors for longer stay should be considered in the decision for or against reoperation in equivocal situations.

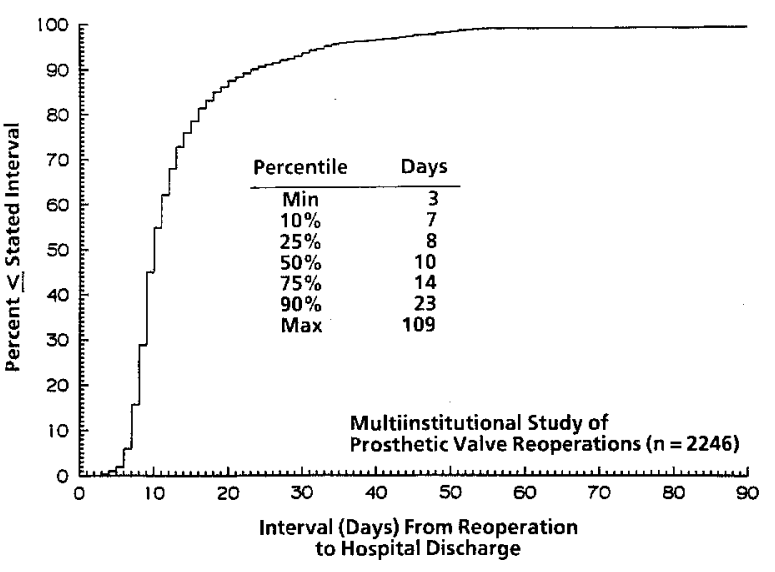

Fig. 5. Cumulative frequency distribution of the interval between reoperation and hospital dismissal. Time zero is the time of the reoperation.

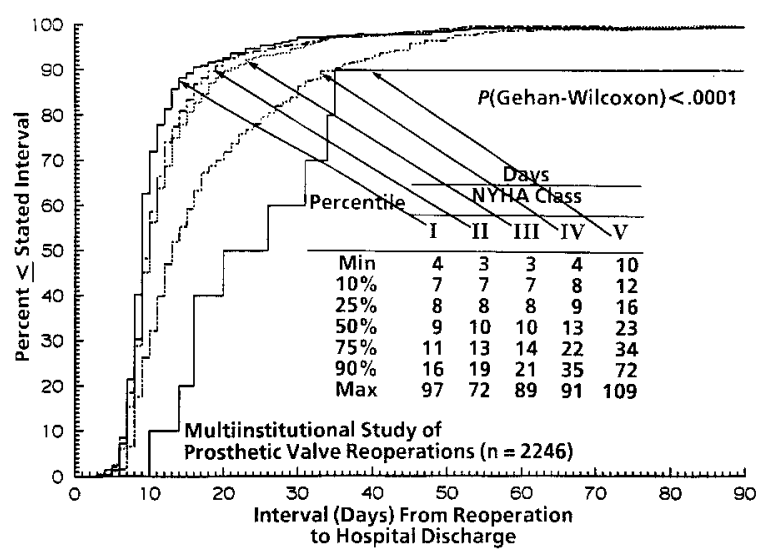

Fig. 6. Cumulative frequency distribution of the interval between reoperation and hospital dismissal, stratified according to the preoperative NYHA functional class. Time zero is the time of the reoperation.

Use of the predictive risk equation. It would have been desirable for hospital mortality to be accurately predicted by use of a small number of simple variables that would have permitted graphic representation of the entire equation. However, the condition of patients coming to reoperation, as evidenced in this study, is sufficiently complex that prediction of risk requires consideration of at least a dozen factors, and these cannot be encompassed by simple nomograms. Thus we recommend that the equation (Appendix C) be solved for each patient, including the calculation of confidence limits to properly interpret the predictions. 
Table V. Risk-adjusted predicted interval (days) from a first reoperation after mitral valve replacement to hospital dismissal, in a basically uncomplicated patient (other than NYHA class), according to the age at reoperation and the preoperative NYHA functional class. The table is a digital nomogram of a specific solution of the multivariable equation in Appendix Table D-1

\begin{tabular}{|c|c|c|c|c|c|c|c|c|c|c|}
\hline \multirow{3}{*}{$\begin{array}{c}\text { Age at } \\
\text { reoperation } \\
(y r)\end{array}$} & \multicolumn{10}{|c|}{ Preoperative NYHA class } \\
\hline & \multicolumn{2}{|c|}{$I$} & \multicolumn{2}{|c|}{$I I$} & \multicolumn{2}{|c|}{$I I I$} & \multicolumn{2}{|c|}{$I V$} & \multicolumn{2}{|c|}{$V$} \\
\hline & Days & $C L$ & Days & $C L$ & Days & $C L$ & Days & $C L$ & Days & $C L$ \\
\hline 20 & 7 & $4-13$ & 7 & $5-14$ & 8 & $5-15$ & 9 & $5-17$ & 13 & $7-31$ \\
\hline 30 & 7 & $4-13$ & 7 & $5-14$ & 8 & $5-15$ & 9 & $5-17$ & 13 & $7-30$ \\
\hline 40 & 7 & $4-13$ & 7 & $5-14$ & 8 & $5-15$ & 9 & $5-17$ & 13 & $7-31$ \\
\hline 50 & 7 & $5-14$ & 8 & $5-14$ & 8 & $5-16$ & 9 & $5-18$ & 14 & $7-32$ \\
\hline 60 & 8 & $5-15$ & 8 & $5-15$ & 9 & $5-17$ & 9 & $6-19$ & 15 & $8-36$ \\
\hline 70 & 8 & $5-16$ & 9 & $5-17$ & 9 & $6-19$ & 10 & $6-21$ & 17 & $8-41$ \\
\hline 80 & 9 & $6-19$ & 10 & $6-20$ & 11 & $6-22$ & 12 & $7-25$ & 19 & $9-50$ \\
\hline
\end{tabular}

$C L, 90 \%$ confidence limits; NYHA, New York Heart Association.

The equation may appear intimidating but, on examination, requires information concerning twelve variables readily accessible in all patients for whom reoperative valve surgery is contemplated. In most instances the majority of these variables will have a value of zero (no risk factor present), and this simplifies the computations. The actual mathematics of the equation requires use of the natural exponential function and otherwise simple multiplications, additions, and subtractions, all within the scope of small programmable calculators.

The prediction of the risk of hospital mortality has many potential applications. First, it should be beneficial in preoperative counseling for the patient and family. For example, prophylactic removal of a Björk-Shiley $60^{\circ}$ convexo-concave mitral prosthesis (Shiley, Inc., Irvine, Calif.) could be under consideration for a 55-year-old, $61 \mathrm{~kg}$, otherwise well patient, with no comorbid conditions. What is the risk of hospital mortality at a contemplated first reoperation? Referring to Appendix 2, one would enter age 55 years, weight $61 \mathrm{~kg}$, NYHA class I (1), stable hemodynamics (0), renal failure-no (0), double valve disease-no (0), tricuspid incompetence-no $(0)$, prosthetic valve endocarditis-no $(0)$, number of previous heart operations (1), ascending aortic aneurysm-no (0), left ventricular aneurysm-no $(0)$, and coronary revascularization-no $(0)$. Solving the equation for the probability of hospital mortality yields $1.5 \%$, with $90 \%$ CLs of $1.1 \%$ to $2.2 \%$. As would be typical of such patients, most of the twelve variables in the equation equal 0 , so that only age, weight, NYHA class, and number of previous operations are relevant to the calculations.

In contrast, consider a 68-year-old patient with chronic heart failure (NYHA class III), with chronic renal failure, tricuspid incompetence, and important symptoms related to ischemic heart disease. The risk in such a patient of a first prosthetic valve reoperation directed to either the aortic or the mitral valve is $43 \%$ ( $90 \%$ CL $33 \%$ to $54 \%$ ). Indeed, such calculations may enter into considerations of medical resource use when calculated risks exceed a particularly high value with reasonable confidence.

Second, use of the equation should be helpful in recommending the appropriateness of bioprosthetic valve implantation and in the timing of reoperation in cases of progressive bioprosthetic valve failure. For example, the estimated hospital mortality of early bioprosthetic valve replacement in a patient now in NYHA class II can be compared with the estimated risk of the same operation at a future time in a more advanced functional class (Figs. 1 to 3 ).

Finally, the ability to predict with reasonable certainty the risk of reoperation in a specific patient has direct application to consideration of prophylactic replacement of Björk-Shiley convexo-concave prosthetic heart valves believed to be at a relatively high risk for outlet strut fracture. ${ }^{22}$ Several analyses offer guidelines for consideration of prophylactic valve replacement, including estimates of linearized risk for structural valve failure, ${ }^{23-25}$ but none provides the other essential data required to assess the advisability of reoperation, namely, patient-specific risk of hospital mortality as provided by this study. 
For example, Marrin, Birkmeyer, and O'Connor ${ }^{25}$ present nomograms for evaluating the benefit of prophylactic reoperation for individual patients with 60-degree convexo-concave valves, the independent variables being the patient's age, linearized outlet strut fracture rate (known for any given valve), and estimated mortality of reoperation. Use of the prediction equation derived in this study permits more accurate patient-specific localization on the nomograms, resulting in credible recommendations regarding the advisability of elective reoperation. The analysis of this problem by Blackstone and Kirklin ${ }^{1}$ would have been further strengthened by availability of such an equation.

Strengths of the study. The three centers participating in the study represent mature valve replacement surgery teams whose combined prosthetic valve reoperation experience is more than 2000 cases, permitting analysis of the entire spectrum of patients undergoing these operations. Although the referral nature of the three practices explains the substantial number of very ill patients coming to reoperation, a particular strength of the combined data set is the experience with the recall of Braunwald-Cutter prostheses (Cutter Biological, Berkeley, Calif.); thus prophylactic valve reoperations constituted about $10 \%$ of the cases, providing valuable data at the opposite clinical extreme. The collaborators included biostatisticians, epidemiologists, physicians, and surgeons with long experience in the field, focused on developing together a usable method for estimating patient-specific risk in future patients, firmly based on a rich set of data.

Limitations of the study. The three participating centers may not be representative of many clinical practices in terms of patient selection, surgical expertise, support services, and other variables. Thus the predicted results may not be obtained in all settings. The uniformity of results within these three institutions after adjustment for case mix (prevalence of risk factors) argues that the data are not extreme and the results predicted should be obtainable in comparable environments.

The prediction equation was based on a specific data set, and its application to another entirely different group of patients (such as a series of future patients or those from another center) remains to be tested. In particular, its application to the dilemma facing younger patients harboring large-sized BjörkShiley convexo-concave mitral valve prostheses is predicated on the finding that valve position is not an incremental risk factor. This finding renders applicable the information from the elective explantation of Braunwald-Cutter aortic valve prostheses, despite its being confined to the aortic rather than to the mitral valve position. ${ }^{2,26}$

Finally, the analysis is of hospital death, not time-related death. The information on hospital mortality is of great interest to patients and their physicians, but "early" deaths after valve operations are not confined to the hospital. ${ }^{27}$

Inferences. The risk of prosthetic valve reoperations is highly variable. Knowledge of the average risk (in this study, 11\%) is of limited value; predicted mortality on the basis of the risk factors found in this study range from near zero to near $100 \%$. The risk of elective, and particularly of prophylactic, reoperations in otherwise well patients is low. If the risk of valve dysfunction is highest in young patients (as is true of xenografts and probably of the Björk-Shiley convexo-concave prosthesis) and the risk of reoperation is low (3\% or less), then consideration of elective and even prophylactic reoperations needs to be entertained. This study provides a method for quantitating the risk in the form of a mathematical equation to facilitate these considerations.

We thank the cardiovascular surgeons of the participating institutions for making their patients available to this study. The intense and prolonged work of Mr. Rob Brown with the database and with many of the analyses is gratefully acknowledged. We thank Ms. Debbie Nuby for her careful work with the manuscript, tables, and graphics. We appreciate also the editorial assistance of Dr. John W. Kirklin in the preparation of this manuscript.

\section{REFERENCES}

1. Blackstone EH, Kirklin JW. Recommendations for prophylactic removal of heart valve prostheses. J Heart Valve Dis 1992;1:3-14.

2. Husebye DG, Pluth JR, Piehler JM, et al. Reoperation on prosthetic heart valves. J THORAC CARDIOVASC SURG 1983;86:543-52.

3. Cohn LH, Aranki SF, Rizzo RJ, et al. Decrease in operative risk of reoperative valve surgery. Ann Thorac Surg 1993;56:15-21.

4. Lytle BW, Cosgrove DM, Taylor PC, et al. Reoperations for valve surgery: perioperative mortality and determinants of risk for 1000 patients, 1958-1984. Ann Thorac Surg 1986;42:632-43.

5. Pansini S, Ottino G, Forsennati PG, et al. Reoperations on heart valve prostheses: an analysis of operative risks and late results. Ann Thorac Surg 1990;50: 590-6.

6. Bosch X, Pomar JL, Pelletier CL, et al. Early and late prognosis after reoperations for prosthetic valve re- 
placement. J Thorac CardiovasC Surg 1984;88:56772.

7. Wideman FE, Blackstone EH, Kirklin JW, et al. Hospital mortality of rereplacement of the aortic valve. J THORAC CARDIOVASC SuRg 1981;82:692-8.

8. Bortolotti U, Milano A, Mossuto E, et al. Early and late outcome after reoperation for prosthetic valve dysfunction: analysis of 549 patients during a 26 year period. J Heart Valve Dis 1994;3:81-7.

9. Antunes MJ, Magalhaes MP. Isolated replacement of a prosthesis or a bioprosthesis in the mitral valve position. Am J Cardiol 1987;59:346-9.

10. SAS Institute Inc., The VARCLUS Procedure, SAS/ STAT User's Guide, version 6, 4th ed, vol 2. Cary, NC: SAS Institute Inc, 1989:1641-59.

11. Walker SH, Duncan DB. Estimation of the probability of an event as a function of several independent variables. Biometrika 1967;54:167-79.

12. Agresti A. Categorical data analysis. New York: John Wiley, 1990:210-60.

13. Baskerville JC, Toogood JH. Guided regression modeling for prediction and exploration of structure with many explanatory variables. Technometrics 1982;24: 9-17.

14. Hosmor DW, Lemeshow S. Applied logistic regression. New York: John Wiley, 1989:82-134.

15. Altman DG, Andersen PK. Bootstrap investigation of the stability of a Cox regression model. Stat Med 1989;8:771-83.

16. Efron RB, Gong G. A leisurely look at the bootstrap, the jackknife, and cross-validation. Am Stat 1983;37: 36-48.

17. Lytle BW, Cosgrove DM, Taylor PC, et al. Primary isolated aortic valve replacement: early and late results. J Thorac Cardiovasc Surg 1989;97:675-94.

18. DiLello F, Flemma RJ, Anderson AJ, et al. Improved early results after aortic valve replacement: analysis by surgical time frame. Ann Thorac Surg 1989;47:51-6.

19. Craver JM, Weintraub WS, Jones EL, et al. Predictors of mortality, complications, and length of stay in aortic valve replacement for aortic stenosis. Circulation 1988;78(Suppl):I85-90.

20. Teoh KH, Ivanov J, Weisel RD, et al. Determinants of survival and valve failure after mitral valve replacement. Ann Thorac Surg 1990;49:643-8.

21. He G, Hughes CF, McCaughan B, et al. Mitral valve replacement combined with coronary artery operation: determinants of early and late results. Ann Thorac Surg 1991;51:916-23.

22. Ericsson A, Lindblom D, Semb G, et al. Strut fracture with Björk-Shiley 70 degrees convexo-concave valve: an international multi-institutional follow-up study. Cardiothorac Surg 1992;6:339-46.

23. Birkmeyer JD, Marrin CAS, O'Connor GT. Should patients with Björk-Shiley valves undergo prophylactic replacement? Lancet 1992;340:520-3.

24. van der Meulen JHP, Steyerberg EW, van der Graaf $\mathrm{Y}$, et al. Age thresholds for prophylactic replacement of Björk-Shiley convexo-concave heart valves: a clinical and economic evaluation. Circulation 1993;88: 156-64.

25. Marrin CAS, Birkmeyer JD, O'Connor GT. The Björk-Shiley dilemma. Ann Thorac Surg 1993;55: 1361-4.

26. Blackstone EH, Kirklin JW, Pluth JR, Turner ME, Parr GVS. The performance of the Braunwald-Cutter aortic prosthetic valve. Ann Thorac Surg 1977;23:30218.

27. Blackstone EH, Kirklin JW. Death and other timerelated events after valve replacement. Circulation 1985;72:753-67.

Appendix Table A-1. The risk-unadjusted relation of the procedure performed at reoperation to the hospital mortality

\begin{tabular}{lrrrr}
\hline $\begin{array}{c}\text { Procedure performed at } \\
\text { reoperation on valve replacement } \\
\text { device }\end{array}$ & $n$ & \multicolumn{3}{c}{ Hospital deaths } \\
\cline { 3 - 5 } & $n$ & No. & $\%$ & CL (\%) \\
\hline Replacement of prosthesis & 1888 & 209 & 11.1 & $9.9-12.3$ \\
Suture repair of leak & 256 & 27 & 10.5 & $7.6-14.3$ \\
Poppet replacement & 53 & 3 & 5.7 & $1.8-14.6$ \\
Thrombectomy of prosthesis & 19 & 1 & 5.3 & $0.4-24$ \\
All others (including multivalve & 30 & 3 & 10 & \\
$\quad$ procedures) & & & & \\
$P\left(\chi^{2}\right)$ & 2246 & 243 & 10.7 & $9.8-12.0$ \\
Total & & & 10.8 & \\
\hline
\end{tabular}

$C L, 90 \%$ confidence limits. 
Appendix Table A-2. The risk-unadjusted relation of concomitant procedures performed at reoperation to the hospital mortality

\begin{tabular}{lcccccc}
\hline & & \multicolumn{3}{c}{ Hospital deaths } & \multicolumn{2}{c}{ Unknown } \\
\cline { 3 - 5 } Concomitant procedure & $n$ & No. & $\%$ & CL (\%) & $n($ deaths) \\
\hline Coronary artery bypass grafting & 196 & 32 & 16.3 & $12.2-21$ & $0(0)$ \\
Ascending aortic aneurysmectomy & 73 & 16 & 22 & $14.5-32$ & $9(0)$ \\
$\quad$ Composite graft technique & 49 & 14 & 29 & $18.4-41$ & $0(0)$ \\
$\quad$ Interposition graft & 24 & 2 & 8.3 & $1.8-25$ & $9(0)$ \\
Left ventricular aneurysmectomy & 10 & 4 & 40 & $16.0-69$ & $8(0)$ \\
Aortic root repair & 149 & 21 & 14.1 & $9.8-19.8$ & $4(0)$ \\
Repair of LV rupture & 7 & 4 & 57 & $24-86$ & $9(0)$ \\
LV outflow enlargement & 20 & 4 & 20 & $7.7-41$ & $4(0)$ \\
None of the above & 1848 & 177 & 9.6 & $8.9-10.3$ & $2(0)$ \\
\hline
\end{tabular}

$C L, 90 \%$ confidence limits; $L V$, left ventricular.

Note: (1) Categories are not mutually exclusive. (2) Data about concomitant procedures other than those above were not collected.

Appendix Table A-3. Indications for the 2246 reoperations on a valve replacement device

\begin{tabular}{lcccc}
\hline \multicolumn{1}{c}{ Indication for reoperation } & & \multicolumn{3}{c}{ Hospital deaths } \\
\cline { 3 - 5 } & $n$ & No. & $\%$ & CL (\%) \\
\hline Periprosthetic leakage without evidence of infection & 600 & 64 & 10.7 & $8.7-13.0$ \\
Degeneration of bioprosthesis & 558 & 47 & 8.4 & $6.6-10.7$ \\
Prosthetic valve endocarditis & 243 & 58 & 24 & $19.5-29$ \\
Structural failure of mechanical prosthesis & 202 & 21 & 10.4 & $7.2-14.7$ \\
Prophylactic device removal or repair & 193 & 2 & 1.0 & $0.2-3.5$ \\
Tissue ingrowth & 121 & 14 & 11.6 & $7.3-17.7$ \\
Patient-prosthesis mismatch & 100 & 10 & 10.0 & $5.7-16.6$ \\
Device thrombosis & 75 & 16 & 21 & $14.1-31$ \\
Multiple thromboemboli & 70 & 5 & 7.1 & $3.0-14.8$ \\
Hemolysis & 52 & 5 & 9.6 & $4.1-19.6$ \\
Concomitant cardiac surgery & 43 & 7 & 16.3 & $8.2-28.8$ \\
Structural failure of unspecified type prosthesis & 17 & 1 & 5.9 & $0.4-26$ \\
Anticoagulant intolerance & 8 & 0 & 0 & $0-34$ \\
Other (unspecified) & 6 & 0 & 0 & $0-41$ \\
Unknown & 10 & 0 & 0 & $0-28$ \\
\hline
\end{tabular}

CL, $90 \%$ confidence limits.

Note: (1) Categories are not mutually exclusive, because different indications could be specified for each prosthesis in place at the time of reoperation. (2) only 50 patients who had multiple valve reoperations had two different indications for reoperation. None had three indications. There were 21 different combinations of the above indications, with the largest group being 8 .

Appendix Table A-4. The risk-unadjusted relation of coexisting morbid conditions at reoperation to the hospital mortality

\begin{tabular}{|c|c|c|c|c|c|}
\hline \multirow[b]{2}{*}{ Coexisting morbid condition } & \multirow[b]{2}{*}{$n$} & \multicolumn{3}{|c|}{ Hospital deaths } & \multirow{2}{*}{$\begin{array}{l}\text { Unknown } \\
n \text { (deaths) }\end{array}$} \\
\hline & & No. & $\%$ & $C L(\%)$ & \\
\hline Cerebrovascular disease & 225 & 25 & 11.1 & $7.9-15.3$ & $61(11)$ \\
\hline Previous myocardial infarction & 134 & 26 & 19.4 & $14.1-26$ & $44(9)$ \\
\hline Chronic obstructive pulmonary disease & 92 & 14 & 15.2 & $9.6-23$ & $59(11)$ \\
\hline Diabetes & 84 & 14 & 16.7 & $10.6-25$ & $63(9)$ \\
\hline Oral medication & 36 & 7 & 19.4 & $9.9-34$ & $57(9)$ \\
\hline Insulin & 48 & 7 & 14.6 & $7.3-26$ & $61(9)$ \\
\hline Renal failure & 57 & 19 & 33 & $23-45$ & $40(7)$ \\
\hline None of the above & 1753 & 156 & 8.9 & $7.8-10.1$ & $12(3)$ \\
\hline
\end{tabular}

$C L, 90 \%$ confidence limits.

Note: (1) Categories are not mutually exclusive. (2) Data about coexisting medical conditions other than those above were not collected. 
Appendix Table A-5. The type of single valve replacement device in place before reoperation, the prevalence and mortality of repair of those devices, and the type of valve replacement device in place after the reoperation in those in whom the device was replaced. Among the patients with a single aortic replacement device in place, 92 ( 17 hospital deaths) had also at reoperation a primary replacement of a mitral valve, along with replacement of the tricuspid valve in two others. Eighty-five (11 hospital deaths) of those with a single mitral replacement device in place preoperatively also underwent a first replacement of the aortic valve, and 14 (four hospital deaths) others had also replacement of the tricuspid valve, while four others (two hospital deaths) had also primary replacement of the aortic and tricuspid valves. Among the patients with a tricuspid valve in place, one (who survived) also had a first replacement of the aortic and mitral valves.

\begin{tabular}{|c|c|c|c|c|c|c|c|c|c|c|c|c|}
\hline \multirow[b]{3}{*}{ Type of device } & \multicolumn{4}{|c|}{$\begin{array}{l}\text { Device in place before } \\
\text { reoperation }\end{array}$} & \multicolumn{4}{|c|}{ Repairs } & \multicolumn{4}{|c|}{$\begin{array}{l}\text { Device in place after } \\
\text { reoperation if valve replaced }\end{array}$} \\
\hline & \multirow[b]{2}{*}{$n$} & \multicolumn{3}{|c|}{ Hospital deaths } & \multirow[b]{2}{*}{$n$} & \multicolumn{3}{|c|}{ Hospital deaths } & \multirow[b]{2}{*}{$n$} & \multicolumn{3}{|c|}{ Hospital deaths } \\
\hline & & No. & $\%$ & $C L(\%)$ & & No. & $\%$ & $C L(\%)$ & & No. & $\%$ & $C L(\%)$ \\
\hline \multicolumn{13}{|l|}{ Isolated aortic } \\
\hline Aortic allograft & 183 & 7 & 3.8 & $1.9-7.3$ & 1 & 0 & 0 & $0-93$ & 44 & 5 & 11.4 & $4.9-23$ \\
\hline Aortic xenograft & 292 & 29 & 9.9 & $7.3-13.4$ & 10 & 1 & 10 & $0.7-41$ & 202 & 22 & 10.9 & 7.6-15.3 \\
\hline Aortic mechanical & 714 & 73 & 10.2 & $8.4-12.3$ & 132 & 10 & 7.6 & $4.3-12.7$ & 819 & 70 & 8.5 & $7.0-10.4$ \\
\hline Aortic unknown type & 24 & 1 & 4.2 & $0.3-19.6$ & 2 & 0 & 0 & $0-75$ & 3 & 2 & 0 & $0-93$ \\
\hline \multicolumn{13}{|l|}{ Isolated mitral } \\
\hline Mitral allograft & 1 & 0 & 0 & $0-93$ & 0 & & & & 0 & & & \\
\hline Mitral xenograft & 249 & 30 & 12.0 & $8.9-16.1$ & 20 & 4 & 20 & $7.7-41$ & 133 & 23 & 17.3 & $12.2-24$ \\
\hline Mitral mechanical & 393 & 44 & 11.2 & $8.7-14.2$ & 108 & 7 & 6.5 & $3.2-12.1$ & 392 & 43 & 11.0 & $8.5-14.0$ \\
\hline Mitral unknown type & 16 & 3 & 18.8 & $5.9-42$ & 1 & 0 & 0 & $0-93$ & 5 & 0 & 0 & $0-47$ \\
\hline \multicolumn{13}{|l|}{ Isolated tricuspid } \\
\hline Tricuspid xenograft & 5 & 1 & 20 & $1.4-65$ & 0 & & & & 5 & 1 & 20 & $1.4-65$ \\
\hline Tricuspid mechanical & 5 & 1 & 20 & $1.4-65$ & 1 & 1 & 100 & $7-100$ & 4 & 0 & 0 & $0-54$ \\
\hline More than one device in place & 364 & 54 & 14.8 & $11.9-18.3$ & & & & & & & & \\
\hline Total & 2246 & 243 & 10.8 & $9.8-12.0$ & & & & & & & & \\
\hline
\end{tabular}

$C L, 90 \%$ confidence limits.

Appendix Table A-6. The risk-unadjusted relation of the position of the valve prosthesis before reoperation to the hospital mortality

\begin{tabular}{|c|c|c|c|c|}
\hline \multirow{2}{*}{$\begin{array}{c}\text { Position of the valve prosthesis } \\
\text { before reoperation }\end{array}$} & \multirow[b]{2}{*}{$n$} & \multicolumn{3}{|c|}{ Hospital deaths } \\
\hline & & No. & $\%$ & $C L(\%)$ \\
\hline One prosthesis & 1882 & 189 & 10.0 & $8.9-11.3$ \\
\hline Aortic & 1213 & 110 & 9.1 & $7.8-10.6$ \\
\hline Mitral & 659 & 77 & 11.7 & $9.7-14.0$ \\
\hline Tricuspid & 10 & 2 & 20 & $4.4-51$ \\
\hline Two prostheses & 332 & 51 & 15.4 & 12.3-19.1 \\
\hline Aortic and mitral & 284 & 41 & 14.4 & $11.2-18.4$ \\
\hline Mitral and tricuspid & 46 & 10 & 22 & $12.6-34$ \\
\hline Aortic and tricuspid & 2 & 0 & 0 & $0-75$ \\
\hline Three prostheses & 32 & 3 & 9.4 & $2.9-23$ \\
\hline Aortic and mitral and tricuspid & 32 & 3 & 9.4 & $2.9-23$ \\
\hline$P\left(\chi^{2}\right)$ for position $(2 \times 7$ table $)$ & & & 0.02 & \\
\hline$P\left(\chi^{2}\right)$ for 1,2, or 3 prostheses & & & 0.02 & \\
\hline$P($ logistic) for 1,2 , or 3 prostheses & & & 0.03 & \\
\hline Total & 2246 & 243 & 10.8 & $9.8-12.0$ \\
\hline
\end{tabular}

$C L, 90 \%$ confidence limits. 
Appendix Table A-7. The risk-unadjusted relation between the era in which the valve reoperation was performed and the hospital mortality

\begin{tabular}{|c|c|c|c|c|c|}
\hline \multicolumn{2}{|c|}{$\begin{array}{c}\text { Date of reoperation } \\
(y r)\end{array}$} & \multirow[b]{2}{*}{$n$} & \multicolumn{3}{|c|}{ Hospital deaths } \\
\hline$\geq$ & $<$ & & No. & $\%$ & $C L(\%)$ \\
\hline & 1965 & 2 & 0 & 0 & $0-75$ \\
\hline 1965. & .1970 & 61 & 9 & 14.8 & $8.2-25$ \\
\hline 1970 . & 1975 & 155 & 16 & 10.3 & $6.7-15.4$ \\
\hline 1975 . & 1980 & 720 & 52 & 7.2 & $5.7-9.1$ \\
\hline 1980. & .1985 & 536 & 82 & 15.3 & $12.8-18.1$ \\
\hline 1985 . & .1990 & 575 & 63 & 11.0 & $8.9-13.4$ \\
\hline 1990 & & 197 & 21 & 10.7 & $7.3-15.1$ \\
\hline \multicolumn{2}{|c|}{$P($ logistic $)$} & & & 0.2 & \\
\hline Total & & 2246 & 243 & 10.8 & $9.8-12.0$ \\
\hline
\end{tabular}

$C L, 90 \%$ confidence limits.

Appendix Table A-8. The risk-unadjusted relation of the priority of reoperation on a valve replacement device to the hospital mortality

\begin{tabular}{|c|c|c|c|c|}
\hline \multirow[b]{2}{*}{ Priority of reoperation } & \multirow[b]{2}{*}{$n$} & \multicolumn{3}{|c|}{ Hospital deaths } \\
\hline & & No. & $\%$ & $C L(\%)$ \\
\hline Elective & 2040 & 172 & 8.4 & $7.5-9.5$ \\
\hline Urgent & 64 & 18 & 28 & $19.2-39$ \\
\hline Emergency & 116 & 49 & 42 & $35-50$ \\
\hline Subtotal & 2220 & 239 & 10.8 & $9.7-11.9$ \\
\hline$P(\operatorname{logistic})$ & & & $<0.0001$ & \\
\hline Unknown & 26 & 4 & 15.4 & $5.9-32$ \\
\hline Total & 2246 & 243 & 10.8 & $9.8-12.0$ \\
\hline
\end{tabular}

$C L, 90 \%$ confidence limits.

\section{Appendix Table B-1. Variables entered into the multivariable analyses}

Patient variables

Demography. Age, gender, origin, height, weight, body surface area, body mass index, ratio of weight to height. Left ventricular function and secondary effects of the valve disease. NYHA class (I to IV; class $\mathrm{V}$ is a moribund condition), hemodynamic state (stable, hemodynamic instability, or cardiogenic shock), urgency of reoperation (elective, urgent, emergency reoperation), left atrial enlargement, left ventricular enlargement, tricuspid valve incompetence (either previously, for which a procedure was performed, or at the time of reoperation).

Indication for reoperation. Prosthetic valve endocarditis, periprosthetic leakage without apparent infection, bioprosthesis degeneration, mechanical prosthesis failure, prosthesis thrombosis, multiple systemic emboli, hemolysis, patient-prosthesis mismatch, anticoagulant intolerance, elective replacement during indicated valve replacement of another native valve.

Previous heart surgery. Interval since last heart valve operation, number of previous valve reoperations, number of previous heart operations, previous aortic valve replacement, previous mitral valve replacement, previous simultaneous aortic and mitral valve replacement, type of prosthesis in place at time of reoperation (allograft, heterograft, mechanical), size of prosthesis in place at the time of reoperation.

Coexisting cardiac conditions. History of myocardial infarction, previous coronary artery bypass grafting, previous percutaneous transluminal coronary angioplasty, history of native valve endocarditis, history of prosthetic valve endocarditis, interval between previous operation and reoperation for prosthetic valve endocarditis, cerebral vascular disease.

Coexisting noncardiac conditions. Renal failure (chronic dialysis or admission creatinine $>2.5 \mathrm{mg} / \mathrm{dl}$ ), diabetes (use of oral hypoglycemics or insulin), chronic pulmonary failure, aneurysm of the ascending aorta.

Procedure variables (only those variables that would be part of the pre-reoperation plan were considered)

Valve reoperation. Position of valve(s) (aortic, mitral tricuspid) on which reoperation (repair or replacement) was performed, type of prosthesis in place at the end of the reoperation (allograft, heterograft, mechanical), prosthesis repair versus replacement.

Concomitant procedures. Repair of ascending aortic aneurysm with simple interposition graft or with composite graft, coronary artery bypass grafting, left ventricular aneurysmectomy, left ventricular outflow tract reconstruction.

Institutional experience variables. Date of reoperation, institution. 
Appendix Table B-2. Frequency of appearance of variables in 1000 separate sampling analyses using automated stepwise multivariable logistic regression (see Patients and methods)

\begin{tabular}{|c|c|c|}
\hline Variable & $n$ & $\%$ of 1000 \\
\hline \multicolumn{3}{|l|}{ Patient variables } \\
\hline \multicolumn{3}{|l|}{ Demographic } \\
\hline Age & 987 & 98.7 \\
\hline Weight & 698 & 69.8 \\
\hline Body surface area & 95 & 9.5 \\
\hline Female & 295 & 29.5 \\
\hline \multicolumn{3}{|c|}{ Left ventricular function and secondary effects of valvular heart disease } \\
\hline NYHA class & 999 & 99.9 \\
\hline Hemodynamic state* & 644 & 64.4 \\
\hline Components of hemodynamic state & 216 & 21.6 \\
\hline Surgical priority* & 208 & 20.8 \\
\hline Components of surgical priority & 169 & 16.9 \\
\hline Tricuspid valve incompetence & 976 & 97.6 \\
\hline Left atrial enlargement & 41 & 4.1 \\
\hline Left ventricular enlargement & 190 & 19.0 \\
\hline \multicolumn{3}{|l|}{ Indications for reoperation } \\
\hline Prosthetic valve endocarditis & 849 & 84.9 \\
\hline Periprosthetic leakage without infection & 51 & 5.1 \\
\hline Prosthesis degeneration & 70 & 7.0 \\
\hline Prosthesis thrombosis & 111 & 11.1 \\
\hline \multicolumn{3}{|l|}{ Previous heart surgery } \\
\hline Number of previous valve reoperations & 173 & 17.3 \\
\hline Number of previous heart operations & 632 & 63.2 \\
\hline Previous aortic valve replacement & 24 & 2.4 \\
\hline Previous mitral valve replacement & 80 & 8.0 \\
\hline Previous aortic and mitral valve replacement & 115 & 11.5 \\
\hline Previous isolated aortic valve replacement & 57 & 5.7 \\
\hline Previous isolated mitral valve replacement & 32 & 3.2 \\
\hline \multicolumn{3}{|l|}{ Type of prosthesis in place before reoperation } \\
\hline Aortic valve allograft & 243 & 24.3 \\
\hline Aortic valve mechanical device & 287 & 28.7 \\
\hline Mitral valve xenograft & 79 & 7.9 \\
\hline \multicolumn{3}{|l|}{ Coexisting and previous cardiac conditions } \\
\hline Ischemic heart disease & 215 & 21.5 \\
\hline History of myocardial infarction & 223 & 22.3 \\
\hline History of native valve endocarditis & 128 & 12.8 \\
\hline History of prosthetic valve endocarditis & 195 & 19.5 \\
\hline History of native valve or prosthetic valve endocarditis & 42 & 4.2 \\
\hline \multicolumn{3}{|l|}{ Coexisting noncardiac conditions } \\
\hline Renal failure & 639 & 63.9 \\
\hline Diabetes & 332 & 33.2 \\
\hline Cerebral vascular disease & 104 & 10.4 \\
\hline Chronic pulmonary failure & 98 & 9.8 \\
\hline Aneurysm of the ascending aorta & 125 & 12.5 \\
\hline \multicolumn{3}{|l|}{ Procedure variables } \\
\hline \multicolumn{3}{|l|}{ Valvular reoperation } \\
\hline Aortic prosthesis reoperation & 95 & 9.5 \\
\hline Aortic prosthesis repair & 0 & 0.0 \\
\hline Aortic prosthesis replacement & 111 & 11.1 \\
\hline Mitral prosthesis reoperation & 42 & 4.2 \\
\hline Mitral prosthesis repair & 1 & 0.1 \\
\hline Mitral prosthesis replacement & 452 & 45.2 \\
\hline \multicolumn{3}{|l|}{ Prostheses in place at end of reoperation } \\
\hline Isolated aortic prosthesis & 36 & 3.6 \\
\hline Isolated mitral prosthesis & 59 & 5.9 \\
\hline Both aortic and mitral prostheses & 430 & 43.0 \\
\hline \multicolumn{3}{|l|}{ Concomitant procedures } \\
\hline Coronary artery bypass grafting & 543 & 54.3 \\
\hline Left ventricular aneurysmectomy & 632 & 63.2 \\
\hline
\end{tabular}


Appendix Table B-2. Cont'd

\begin{tabular}{lcc}
\hline \multicolumn{1}{c}{ Variable } & $n$ & $\%$ of 1000 \\
\hline Enlargement of aortic root & 314 & 31.4 \\
Composite grafting of ascending aortic aneurysm & 785 & 78.5 \\
Institutional variables & & \\
Center & 36 & 3.6 \\
Mayo Clinic & 59 & 5.9 \\
University of Alabama at Birmingham & 44 & 4.4 \\
University of Oregon & & 294 \\
Date of reoperation & 395 & 39.5 \\
Overall & & \\
Pre-1970 & & 39.5 \\
\hline
\end{tabular}

*Ordinal variable.

Appendix Table B-3. Examples of internal validation of the logistic multivariable equation (Table I) in stratified subgroups of patients. The method used for the prediction of the number of hospital deaths in each specific group and the method used to compare actual and predicted hospital mortality are described in the section on Patients and methods. "Ideal" elective reoperation indicates that the patients were without prosthetic valve infection, stable, undergoing a first elective reoperation on a mechanical or heterograft (xenograft) valve, with no concomitant procedure.

\begin{tabular}{|c|c|c|c|c|c|c|c|c|}
\hline \multirow[b]{3}{*}{ Variable } & \multirow[b]{3}{*}{$n$} & \multicolumn{6}{|c|}{ Hospital deaths } & \multirow{3}{*}{$\begin{array}{c}P \\
\text { value }\end{array}$} \\
\hline & & \multicolumn{3}{|c|}{ Actual } & \multicolumn{3}{|c|}{ Predicted } & \\
\hline & & No. & $\%$ & $C L(\%)$ & No. & $\%$ & $C L(\%)$ & \\
\hline \multicolumn{9}{|l|}{ Priority of reoperation } \\
\hline Elective & 2040 & 172 & 8.4 & $7.5-9.5$ & 177.9 & 8.7 & $8.4-9.0$ & 0.7 \\
\hline Urgent & 64 & 18 & 28 & $19.2-39$ & 16.1 & 25.2 & $21-30$ & 0.6 \\
\hline Emergency & 116 & 49 & 42 & $35-50$ & 45.7 & 39.4 & $35-44$ & 0.6 \\
\hline Unknown & 26 & 4 & & & & & & \\
\hline \multicolumn{9}{|l|}{ Position of valve prostheses before reoperation } \\
\hline \multicolumn{9}{|l|}{ One prosthesis } \\
\hline Aortic & 1213 & 110 & 9.1 & $7.8-10.6$ & 104.0 & 8.5 & $8.0-9.1$ & 0.6 \\
\hline Mitral & 659 & 77 & 11.7 & $9.7-14.0$ & 79.4 & 12.1 & $11.2-13.0$ & 0.8 \\
\hline Tricuspid & 10 & 2 & 20 & $4.4-51$ & 2.0 & 19.8 & $10.4-33$ & 0.99 \\
\hline \multicolumn{9}{|l|}{ Two prostheses } \\
\hline Aortic and mitral & 284 & 41 & 14.4 & $11.2-18.4$ & 42.6 & 15.0 & $13.7-16.4$ & 0.8 \\
\hline Mitral and tricuspid & 46 & 10 & 22 & $12.6-34$ & 9.1 & 19.7 & $16.2-24$ & 0.7 \\
\hline Aortic and tricuspid & 2 & 0 & 0 & $0-75$ & 0.2 & 9.8 & $5.8-13.7$ & 0.6 \\
\hline \multicolumn{9}{|l|}{ Three prostheses } \\
\hline Aortic and mitral and tricuspid & 32 & 3 & 9.4 & $2.9-23$ & 5.7 & 17.9 & $14.5-13.5$ & 0.5 \\
\hline \multicolumn{9}{|l|}{ Surgical center } \\
\hline Mayo Clinic & 997 & 98 & 9.8 & $8.3-11.5$ & 96.9 & 9.7 & $9.1-10.3$ & 0.9 \\
\hline University of Alabama & 861 & 96 & 11.1 & 9.5-13.1 & 98.2 & 11.4 & $10.6-12.3$ & 0.8 \\
\hline University of Oregon & 388 & 49 & 12.7 & $10.0-15.8$ & 47.9 & 12.4 & $11.3-13.5$ & 0.9 \\
\hline $\begin{array}{l}\text { Stable, noninfected patients undergoing elec- } \\
\text { tive reoperation }\end{array}$ & & & & & & & & \\
\hline \multicolumn{9}{|l|}{ NYHA class } \\
\hline I & 270 & 6 & 2.2 & $1.0-4.5$ & 5.2 & 1.9 & $1.8-2.1$ & 0.7 \\
\hline II & 507 & 23 & 4.5 & $3.2-6.4$ & 22.6 & 4.5 & $4.2-4.8$ & 0.9 \\
\hline III & 779 & 67 & 8.6 & $7.0-10.5$ & 67.9 & 8.7 & $8.4-9.1$ & 0.9 \\
\hline IV & 245 & 38 & 15.5 & $11.9-19.9$ & 42.6 & 17.4 & $16.3-18.5$ & 0.6 \\
\hline Unknown & 32 & 2 & & & & & & \\
\hline \multicolumn{9}{|l|}{ "Ideal" elective reoperations } \\
\hline \multicolumn{9}{|l|}{ NYHA class } \\
\hline I & 150 & 2 & 1.3 & $0.3-4.4$ & 2.6 & 1.8 & $1.7-1.9$ & 0.7 \\
\hline II & 225 & 6 & 2.7 & $1.2-5.4$ & 8.6 & 3.8 & $3.6-4.1$ & 0.6 \\
\hline III & 306 & 23 & 7.5 & $5.3-10.6$ & 23.9 & 7.8 & $7.4-8.2$ & 0.8 \\
\hline
\end{tabular}

$C L, 90 \%$ confidence limits; NYHA, New York Heart Association. 


\section{Appendix C. Pseudocode for the estimation of patient-specific (risk-adjusted) hospital mortality after heart valve reoperation and its confidence limits}

Values for twelve patient characteristics and anticipated surgical variables are required to solve the risk factor equation for the probability of hospital mortality and its degree of uncertainty. The following formal statements (computer pseudocode) provide the information required to write programmable calculator or computer software code to accomplish this.

Definition of the names of variables

Let the following variable names be defined:

NYHA = Patient's NYHA class in numerical terms, 1 through 5 (5 is shock) corresponding to clinical classes I, II, III, IV, and V.

HD2STATE = Patient's hemodynamic state at reoperation, coded as $0=$ stable, $1=$ hemodynamically unstable, $4=$ cardiogenic shock (this is a squared transform of the ordinal relationship $0,1,2)$.

AGE2YRS $=[\text { Patient's age (years) } / 50]^{2}$ (this is a scaled squared transform).

INVWGTKG $=70 /[$ patient's weight $(\mathrm{kg})]$ (this is a scaled inverse transformation).

RENAL $=$ Does patient have chronic renal failure or creatinine $>2.5 \mathrm{mg} / \mathrm{dl}(0=$ no, 1 = yes)?

DOUBLE $=$ Does patient have multiple valve disease at the time of reoperation such that either (a) both aortic and mitral valves have in the past been replaced or (b) it is anticipated that at the end of the reoperation, both mitral and aortic prostheses will be in place $(0=$ no, $1=$ yes $)$ ?

TVINCOMP $=$ Does patient presently have, or has the patient had in the past, important tricuspid valve incompetence, requiring intervention $(0=$ no, $1=$ yes $)$ ?

PVE $=$ Does the patient have active prosthetic valve endocarditis at the time of reoperation $(0=$ no, $1=$ yes)?

OPENNUMB $=$ The number of previous open heart operations this patient has had in the past $(1$ for the anticipated first reoperation after a primary valve replacement, for example).

$\mathrm{AAA}=$ Is repair of an ascending aortic aneurysm, using the composite graft technique, anticipated $(0=$ no, $1=$ yes)?

LVA $=$ Is resection of a left ventricular aneurysm anticipated $(0=$ no, $1=$ yes)?

$\mathrm{CABG}=\mathrm{Is}$ coronary artery bypass grafting anticipated $(0=$ no, $1=$ yes $)$ ?
For each patient being evaluated, values for each of the above-defined variables will be substituted for the variable names. For example, a patient in NYHA class III will have the number 3 substituted for the variable name NYHA wherever it appears in the following statements.

Point estimate (the probability of hospital mortality)

Calculate the estimate of hospital mortality in logit units:

$$
\begin{aligned}
\text { LOGIT }= & -6.44434+0.57445 \cdot \text { NYHA }+0.56473 \cdot \\
& \text { HD2STATE }+0.64274 \cdot \text { AGE2YRS }+0.52704 \cdot \\
& \text { INVWGTKG }+0.88591 \cdot \text { RENAL }+0.50879 \cdot \\
& \text { DOUBLE }+0.86470 \cdot \text { TVINCOMP }+1.15119 \cdot \\
& \text { PVE }+0.33105 \cdot \text { OPENNUMB }+1.49854 \cdot \\
& \text { AAA }+1.99283 \cdot \mathrm{LVA}+0.60047 \cdot \text { CABG }
\end{aligned}
$$

Transform the logit units into the estimated probability of hospital death, using the logistic equation:

$$
\mathrm{P}=1 /(1+\mathrm{EXP}[-\mathrm{LOGIT}])
$$

where EXP is the natural exponential function. (P can be converted to percent by multiplying it by 100 .)

Confidence limits (interval) around the point estimate. Asymptotic, asymmetric confidence interval calculations require using the variance-covariance matrix that is generated as part of the logistic regression analysis. In this pseudocode, the matrix calculations are presented in linear expression form. Thus the variance components appear as squared terms multiplied by the square of a single risk factor while covariance components appear as risk factor pairs. The latter are multiplied by 2 because they appear twice in the matrix.

Let:

$$
\begin{aligned}
& \mathrm{XSX}=0.19593+0.00987 \cdot \mathrm{NYHA}^{2}+0.01228 \cdot \\
& \text { HD2STATE }^{2}+0.01620 \cdot \text { AGE2YRS }^{2}+0.02495 \text {. } \\
& \text { INVWGTKG }^{2}+0.12093 \cdot \text { RENAL }^{2}+0.02756 \text {. } \\
& \text { DOUBLE }^{2}+0.04267 \cdot \text { TVINCOMP }^{2}+0.03822 \text {. } \\
& \text { PVE }^{2}+0.01069 \cdot \mathrm{OPENNUMB}^{2}+0.13998 \cdot \mathrm{AAA}^{2} \\
& +0.49826 \cdot \mathrm{LVA}^{2}+0.05291 \cdot \mathrm{CABG}^{2}+2 \text {. } \\
& \{-0.02715 \cdot \text { NYHA }+0.00957 \cdot \text { HD2STATE - } \\
& 0.03013 \cdot \text { AGE2YRS }-0.03190 \cdot \text { INVWGTKG }+ \\
& 0.00024 \cdot \text { RENAL }-0.00602 \cdot \text { DOUBLE }-0.00047 \\
& \cdot \text { TVINCOMP }-0.01447 \cdot \text { PVE }-0.01494 \cdot \text { OPEN- } \\
& \text { NUMB }-0.02134 \cdot \text { AAA }-0.02469 \cdot \text { LVA - } \\
& 0.00370 \cdot \mathrm{CABG}\}+2 \cdot \mathrm{NYHA} \cdot\{-0.00544 \cdot \\
& \text { HD2STATE }-0.00017 \cdot \text { AGE2YRS }-0.00011 \text {. } \\
& \text { INVWGTKG }-0.00251 \cdot \text { RENAL }-0.00141 \cdot \\
& \text { DOUBLE - } 0.00206 \cdot \text { TVINCOMP }-0.00125 \cdot \\
& \text { PVE }-0.00116 \cdot \text { OPENNUMB }+0.00131 \cdot \mathrm{AAA}+ \\
& 0.00408 \cdot \text { LVA }-0.00093 \cdot \mathrm{CABG}\}+2 \text {. } \\
& \text { HD2STATE } \cdot\{0.00098 \cdot \text { AGE2YRS + } 0.00052 \cdot \\
& \text { INVWGTKG }-0.00115 \cdot \text { RENAL }+0.00149 \text {. } \\
& \text { DOUBLE }+0.00286 \text {. TVINCOMP }+0.00079 \text {. } \\
& \text { PVE }+0.00108 \cdot \text { OPENNUMB }+0.00119 \cdot \text { AAA }+ \\
& 0.00020 \cdot \mathrm{LVA}+0.00245 \cdot \mathrm{CABG}\}+2 \cdot \text { AGE2YRS } \\
& \text { - }\{0.00324 \cdot \text { INVWGTKG }-0.00155 \cdot \text { RENAL }+
\end{aligned}
$$


DOUBLE $-0.00136 \cdot$ TVINCOMP +0.00192 . PVE $-0.00076 \cdot$ OPENNUMB $+0.00339 \cdot$ AAA + $0.00165 \cdot \mathrm{LVA}+0.00114 \cdot \mathrm{CABG}\}+2 \cdot \mathrm{RENAL} \cdot$ $\{0.00294 \cdot$ DOUBLE $+0.00214 \cdot$ TVINCOMP $0.00094 \cdot \mathrm{PVE}+0.00068 \cdot \mathrm{OPENNUMB}+0.00608$ - AAA $-0.00766 \cdot$ LVA $-0.00034 \cdot \mathrm{CABG}\}+2 \cdot$ DOUBLE $\cdot\{-0.00163 \cdot$ TVINCOMP $+0.00403 \cdot$ PVE $-0.00123 \cdot$ OPENNUMB $+0.00370 \cdot$ AAA $0.00278 \cdot \mathrm{LVA}+0.00295 \cdot \mathrm{CABG}\}+2 \cdot \mathrm{TVIN}-$ COMP $\cdot\{0.00471 \cdot \mathrm{PVE}-0.00117 \cdot$ OPENNUMB $+0.00540 \cdot \mathrm{AAA}+0.00557 \cdot \mathrm{LVA}+0.00454$. CABG $\}+2 \cdot$ PVE $\cdot\{0.00037 \cdot$ OPENNUMB $0.00569 \cdot$ AAA $-0.00200 \cdot$ LVA $+0.00225 \cdot$ CABG $\}+2 \cdot$ OPENNUMB $\cdot\{0.00001 \cdot \mathrm{AAA}+$ $0.00279 \cdot \mathrm{LVA}+0.00090 \cdot \mathrm{CABG}\}+2 \cdot \mathrm{AAA} \cdot$ $\{0.00749 \cdot \mathrm{LVA}+0.00018 \cdot \mathrm{CABG}\}-0.00912 \cdot 2 \cdot$ LVA $\cdot$ CABG

The asymptotic standard error of LOGIT is estimated by:

$$
\text { SELOGIT }=\text { SQRT }[X S X]
$$

where SQRT is the square root function.

Calculation of the upper and lower confidence limits requires a confidence coefficient to be specified (designated below as CONFC). For approximately $70 \%$ confidence limits equivalent to plus and minus one standard deviation of the point estimate $P$, the confidence coefficient is 1 . For $95 \%$ intervals ( 2 standard deviations) the confidence coefficient CONFC is approximately 2. For $90 \%$ intervals used in this paper, the confidence coefficient was 1.645 .

Let:

\section{$\mathrm{CONFC}=$ Confidence coefficient}

Then the lower and upper limits of the confidence interval about LOGIT are estimated as:

$$
\begin{aligned}
& \text { LCLOGIT }=\text { LOGIT }- \text { CONFC } \cdot \text { SELOGIT } \\
& \text { UCLOGIT }=\text { LOGIT }+ \text { CONFC } \cdot \text { SELOGIT }
\end{aligned}
$$

These symmetric confidence limits are transformed into asymmetric confidence limits about $\mathrm{P}$ by:

$$
\begin{aligned}
\mathrm{LCP} & =1 /(1+\mathrm{EXP}[-\mathrm{LCLOGIT}]) \\
\mathrm{UCP} & =1 /(1+\mathrm{EXP}[-\mathrm{UCLOGIT}])
\end{aligned}
$$

Verification of code. The following values for variables may be used to test each portion of the calculator or computer code generated from the above information. Substitute into the variable names the following nonsensible values (chosen not to be the characteristics of any patient, but rather to exercise every part of the equation simultaneously to check for errors): $\mathrm{NYHA}=3$, HD2STATE $=0.25$, AGE2YRS $=1.0404$, INVWGTKG $=1.07692$, RENAL $=0.14$, DOUBLE $=0.2$, TVIN$\mathrm{COMP}=0.13, \mathrm{PVE}=0.12, \mathrm{OPENNUMB}=1.5, \mathrm{AAA}=$ $0.11, \mathrm{LVA}=0.16$, and $\mathrm{CABG}=0.24$. Choose $\mathrm{CONFC}=$ 1.64485 . With these values substituted into the equations (program), LOGIT $=-1.74280, \mathrm{P}=0.14896, \mathrm{XSX}=$ 0.021510, SELOGIT $=0.14666$, LCLOGIT $=-1.98404$, UCLOGIT $=-1.50156, \mathrm{LCP}=0.12089$, and UCP $=$ 0.18219 .

Appendix continues on page 48. 
Appendix Table D-1. Correlates of length of postoperative stay among hospital survivors, determined by multivariable linear regression analysis. The dependent variable was $\ln [\ln ($ length of postoperative stay, days)].

\begin{tabular}{|c|c|c|}
\hline Correlates & Coefficient $\pm S D$ & $P$ value \\
\hline \multicolumn{3}{|l|}{ Demographic } \\
\hline Age* (older) $^{*}$ & $0.143 \pm 0.032$ & $<0.0001$ \\
\hline Age (younger) & $-0.0036 \pm 0.00126$ & 0.005 \\
\hline Race other than white & $0.040 \pm 0.0147$ & 0.006 \\
\hline \multicolumn{3}{|l|}{ Left ventricular function and secondary conditions } \\
\hline NYHA class $(\mathrm{I}-\mathrm{V}) \dagger$ (higher) & $0.0062 \pm 0.00089$ & $<0.0001$ \\
\hline Hemodynamic status (poorer) & $0.066 \pm 0.0187$ & 0.0005 \\
\hline \multicolumn{3}{|l|}{ Extensiveness of valvular heart disease } \\
\hline Previous double or triple valve replacement & $0.031 \pm 0.0113$ & 0.006 \\
\hline \multicolumn{3}{|l|}{ Previous cardiac surgery } \\
\hline Number of previous heart operations (higher) & $0.027 \pm 0.0065$ & $<0.0001$ \\
\hline \multicolumn{3}{|l|}{ Indication for reoperation } \\
\hline Prosthetic valve infection & $0.24 \pm 0.0133$ & $<0.0001$ \\
\hline Tissue ingrowth & $0.062 \pm 0.0179$ & 0.0005 \\
\hline Patient-prosthesis mismatch & $0.060 \pm 0.0188$ & 0.002 \\
\hline Structural failure of mechanical prosthesis & $0.031 \pm 0.0140$ & 0.03 \\
\hline \multicolumn{3}{|l|}{ Coexisting morbid conditions } \\
\hline Renal failure & $0.177 \pm 0.028$ & $<0.0001$ \\
\hline Diabetes & $0.060 \pm 0.020$ & 0.003 \\
\hline Past prosthetic valve infection & $0.040 \pm 0.0159$ & 0.01 \\
\hline \multicolumn{3}{|l|}{ Current position of valve replacement } \\
\hline Mitral valve replacement & $0.051 \pm 0.0085$ & $<0.0001$ \\
\hline Tricuspid valve replacement & $0.050 \pm 0.021$ & 0.02 \\
\hline \multicolumn{3}{|l|}{ Concomitant procedures } \\
\hline Repair of ascending aortic aneurysm by composite graft technique & $0.101 \pm 0.028$ & 0.0004 \\
\hline Coronary artery bypass grafting & $0.042 \pm 0.0140$ & 0.003 \\
\hline \multicolumn{3}{|l|}{ Surgical experience } \\
\hline Date of reoperation $\div$ (earlier) & $-0.151 \pm 0.0118$ & $<0.0001$ \\
\hline \multicolumn{3}{|l|}{ Institution } \\
\hline One institution & $0.030 \pm 0.0080$ & 0.0002 \\
\hline
\end{tabular}

Intercept 1.15. NYHA, New York Heart Association; SD, standard deviation.

* Age (years)/50 $]^{2}$ squared transformation.

$\uparrow$ Squared transformation.

$\$$ Logarithmic transformation of years since January 1, 1963. 